\title{
An Analysis Related To Job Stress \\ (With reference to Healthcare Personnel of Prayagraj Region)
}

\begin{abstract}
Aparajita Singh, Ph.D. Scholar, Joseph School of Business Studies, SHUATS-Prayagraj Dr. Sneh P. Daniel, (Co-author) Assistant Professor, Joseph School of Business Studies, SHUATS-Prayagraj.
\end{abstract}

\author{
Electronic version \\ URL: http://www.researchambition.com \\ DOI: https://doi.org/10.53724/ambition/v5n4.03 \\ ISSN: 2456-0146 \\ Vol. 5, Issue-IV, February 2021 \\ Page No. 06-10 \\ Publisher \\ Welfare Universe \\ email: publish2017@gmail.com
}

CResearch Ambition: An International Multidisciplinary e-Journal 2021. This Open Access article is published under a Creative Commons Attribution Non-Commercial 4.0 International License https://creativecommons.org/licenses/by-nc/4.0/, which permits non-commercial reuse, distribution, and reproduction in any medium, provided the original work is properly cited. For citation use the DOI. For commercial re-use, please contact editor email:- publish2017@ gmail.com By accessing the work you hereby accept the Terms. Non-commercial uses of the work are permitted without any further permission from Research Ambition: An International Multidisciplinary eJournal provided the work is properly attributed. 
Web: www.researchambition.com Email: publish2017@gmail.com

Vol. 5, Issue-IV

Feb. 2021

\title{
An Analysis Related To Job Stress \\ (With reference to Healthcare Personnel of Prayagraj Region)
}

\author{
*Aparajita Singh \\ (Author) \\ ${ }^{* *}$ Dr. Sneh P. Daniel \\ (Co-author)
}

\section{Abstract}

Any change in work, work pattern and working environment which is perceived as of adversial kind can create stress often called a "Silent Killer". Stress is perceptual aspect as what is stress to one may not be stress to another due to perceptual differences. When it comes to the stress in healthcare, by nature highly volatile, highly stressful sector due to large level of unprediction in nature of job, job hours, needs of patients, nature of diseases and treatment required, all are quite variable. Rising complexities in the healthcare sector are compounded with surge in the job expectations and role expectations with the healthcare workers, while at the same there is sharp fall in the numbers of workers willing to serve in the sector. All these prompted to conduct a descriptive research study in healthcare sector with aims to identify the causes behind stress among healthcare workers, nature of stress experienced by them and to arrive with viable techniques of stress management for them. The research design is qualitative by nature, based on the analysis of available secondary data as well as survey of healthcare professionals, staff and support system. The tool used for primary data collection is questionnaire circulated among healthcare professionals and staff of the hospitals in Prayagraj. The study revealed the prime sources of stress and impacts on the service providers as well as on the healthcare sector itself. The research study concluded with some result-oriented measurements to decline the level of stress experienced in general by the healthcare workers and professionals.

Keywords: Stress, Healthcare Workers, Stressors, Source of Stress, Managing Stress.

\section{Objectives}

1. To identify the major sources of stress among healthcare professionals and supporting staff of the sector.

2. To discuss the impacts of identified stressors on health care sector.

3. To provide suggestive techniques to slash down the momentum of stressors and raise quality of work life among healthcare professionals and supporting staff.

\footnotetext{
${ }^{*}$ Ph.D. Scholar, Joseph School of Business Studies, SHUATS-Prayagraj.

${ }^{* *}$ Assistant Professor, Joseph School of Business Studies, SHUATS-Prayagraj.
} 


\section{Introduction}

Stress is the perceived threatening situation to one's physical and mental well-being and it is silent by nature. Different people respond differently towards stress, for some it may be a high level of danger, while for others it may not be so adversial, therefore stress felt depends upon one's perceptual difference. Stress is the result of any change in surrounding circumstances. Stress is caused due to the secretion of excess of adrenalin into the blood, under the influence of perceived danger. It is a response to a threatening event leads to the chemical changes such as increase heartbeat, breathing and also many emotional and behavioural changes. In absence of adrenalin cycle, life will not be possible, there will be no respond to a danger or threat which may harm actually. So, we can say in a way when that stress is useful it is known as eustress. In absence of danger or risk if the adrenal cycle does not stops it becomes harmful and called as distress. There are mainly three stages of stress - Alam stage, Resistance Stage and Exhaustion. Stress is commonly felt by people on account of everyday stressors or factors causing stress, Impact of stress are positive as well as negative, emotional or psychological, such as anxiety, anger, depression, frustration, over reaction, memory loss, fear of unknown, eating disorders, night terrors, phobias, social isolation etc. Various Reasons of Stress. Reasons behind stress are wide, varied and anything depending on one's perception. Some are following- inner conflicts, perceptual influences, job demands, lack of control, role demands, physical demands, inter-personal demands, working environments, peer pressure, social pressure etc. When it comes to the stress on healthcare workers and professionals, it becomes more crucial to have a serious outlook towards stress. It causes impacts and remedies to cut down the level of stress. This is so because healthcare sector is the core and crucial sector for any nation as the level of health of the citizens of a nation is a prime indicator of the progress of a country. Given a look and found that stress level and burnout is very high among healthcare professionals and workers. In a survey conducted in 2019, it has been reported $15 \%$ of nurses have feeling of burnout, added to it the latest dreadful impacts of pandemic COVID-19 mounting the safety pressure on them. It all resulting into alleviating job performance and risk of errors by them. Particularly those working at front line encounter large number of stressors even in routine period of time. Medical professionals, nurses and other supporting staff have ongoing fear of catching virus, emotional trauma over death of patients, facing the anger of patients and attendants.

\section{Review of the Literature:}

Bailey, (1985) ${ }^{\mathbf{1}}$ : In his research identified common sources of stress are workload, patient care, interpersonal relationships with colleagues, knowledge of nursing and nursing skills, type of nursing, and bureaucratic-political constraints.

\footnotetext{
${ }^{1}$ Bailey, R.D., (1985). Coping with stress in caring., Oxford: Blackwell.
} 
Cooper et al.,(1988) ${ }^{2}$ : In a study carried out amongst family doctors, the issues were interruptions during and outside surgery hours and patients demands.

Michie \& Williams (2002): ${ }^{3}$

Review on reducing work related psychological ill health and sickness absence was particularly significant, as it provided an assessment of whether associations between work factors and psychological ill health were similar across sector and across countries.

\section{European Agency for Safety and Health at Work (2005): ${ }^{4}$}

In their study found that work stress is the second most prevalent work-related health problem after backache, affecting 22 percent of workers in 27 European countries.

\section{Hirak Dasgupta and Suresh Kumar (2009): ${ }^{5}$}

Conducted a study where they surveyed one hundred and fifty doctors in a government hospital in Shimla and examined the stress level between male and female doctors in the hospital. The study revealed that there is no difference between the stress levels of male and female doctors except in case of the factors- Role inadequacy and Inter-role distance. And in these factors, the stress level among female doctors is much more than male.

\section{Dola Saha, Rajesh Kumar Sinha, Kankshi Bhavsar, 2011: ${ }^{6}$}

In a study conducted to identify sources of stress in healthcare personnel of each category showed that the prime sources of stress were underpayment, excessive workload, inadequate staff, \& being involved in the emotional distress of patients. They found that a proper workload management policy, adequate delegation of authority along with responsibility, recognition of efforts along with ongoing training, stress and time management will go a long way in managing stress in these personnel.

\section{Suggestive Measures:}

Approaches of stress management can be followed at two levels i.e., individual and organization to yield the effective outcomes. As the individual level stress management techniques can be followed such as time management, inclusion of physical workout, raising social support network, relaxation training, regular connect with friend's family and relatives in order to have an outlet to release, stress of the work and mundane tasks. At the organizational or sectoral level, conduction of stress management training session on regular basis. Running various wellness programs for physical and mental health of

${ }^{2}$ Cooper CL. (1998): Introduction In: C.L. Cooper, Editor, Theories of Organizational Stress, Oxford University Press, Oxford, 1-5.

${ }^{3}$ S Michie, S Williams: Reducing work related psychological ill health and sickness absence: a systematic literature review.

${ }^{4}$ European Agency for Safety And Health At Work. (2002), Working on Stress. Office for Official Publications of the European Communities: Luxemburg.

${ }^{5}$ Hirak, Dasgupta \& Suresh, Kumar, (2009): Role Stress among Doctors Working in a Government Hospital n Shimla (India). European Journal of Social Sciences, 9(3), PP. 356-370

${ }^{6}$ Dola Saha, Rajesh Kumar Sinha, Kankshi Bhavsar, Understanding Job Stress among Healthcare Staff. 
workers, rescheduling and redesigning of job at possible levels can boost. Motivation, morale, esteem of the people.

\section{Recommendations}

Some recommendations for result oriented stress management of healthcare professionals and workers are:-

1. Being aware of stressors- a close observation of factors causing physical, psychological distress can facilitate to develop better outlook to deal, rather than ignoring them, as ignoring is not a solution.

2. Observing Emotional and Physical reaction towards stressors- Notice, list and evaluate the reactions towards stressors can be of big help to change the perception behavioural pattern, simultaneously developing right perception and conduct will alleviate the hazards of stress.

3. Cutting the intensity of Emotional response- over emotional response for the perception of physical danger, emotional danger will lead to the exaggerated of the real situations. Be moderate in reaction lesser will be the experienced stress.

4. Building and maintaining physical and emotional reserves- Regular exercises, meditation, yoga can cut down the effects of stress. Cultivation of mutual relations, friendship and social network help to bring out bottled up emotions, thus reduces stress.

5. Open Communication Channels- Frequently communicate with your supervisor, colleagues and subordinates of the job stress experienced. Open talk sessions about how the job stressors are affecting your performance.

6. Access to mental health resources- ask candidly for help to reach out mental health resources available at the workplace, when mental health is at alarming phase.

7. Inclusion of Micro Breaks- Keeping in mind long, tiring duty hours with no usual breaks. Can be turn into favour through the inclusion and rejoicing micro breaks.

\section{Conclusion:}

It has been reported that cognitively, physical health and performance of nursing staff is greatly affected by stress and stress tolerance ability. Although several studies have been conducted to know the overall influence of stress bearing capacity, perception and coping quotient on the physical and mental well- being of healthcare workers, yet results by far are still not so much in gain. Healthcare professionals and staff are very prone for stressors related with their work and severely affected both physically and mentally. It all lower their work efficiency with many adversial impacts on the hospital, quality of treatment given to the patients and the overall health pool of the nation, at the broadest level. With the help of this research study, significant efforts are done with the view to explore issues of stressors related closely with the occupation of health care professionals and staff and to come with the 
suggestions in the form of changes in behavioural, physical work and routine of them. With a healthy, positive and supportive twist in overall work regime of the healthcare sector great far-reaching results can be obtained surely. Since healthcare centre is the core service providing sector to the human capital of the world, when it comes to the people render service in the sector. Rationality is the requisite of the nature of job so the key Myntra is "Be more reality oriented to keep the stress at bay" fits best on them.

$* * * * * * * * * * * * * * * * * * * * * * *$ 